\title{
Variación morfológica craneofacial en poblaciones humanas de la Quebrada de Humahuaca (Jujuy, Argentina)
}

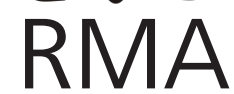

Antropología Biológica

\author{
Lumila P. Menéndez* y Verónica Seldes**
}

* CONICET - Departamento de Antropología, Museo de La Plata - Facultad de Ciencias Naturales y Museo, UNLP, Argentina. lumilam@fcnym.unlp.edu.ar;

** CONICET - Instituto de Ciencia Antropológicas, Sección Antropología

Biológica, Facultad de Filosofía y Letras, UBA. vseldes@gmail.com.

\begin{abstract}
Resumen
El propósito del presente trabajo fue analizar la variación morfológica craneofacial en poblaciones humanas que habitaron la Quebrada de Humahuaca durante el Holoceno tardío. Se estudiaron los cambios en forma y tamaño del esqueleto facial y base craneana, y se evaluó la distribución de la variación morfológica craneofacial en el espacio geográfico. Para esto, se seleccionaron 114 cráneos de individuos adultos de ambos sexos que no presentasen modificaciones culturales o las presentasen en un grado muy leve, procedentes de seis sitios del sector medio de la Quebrada. Se relevaron 41 puntos anatómicos en 3D con un brazo mecánico Microscribe G2X. Para evaluar la variación morfológica se realizó un ANOVA, se calcularon componentes principales y variables canónicas; mientras que la asociación entre morfología y variación espacial fue evaluada a través de un análisis de Procrustes. Los resultados indican que la variación craneofacial difiere según se considere el esqueleto facial ó la base. Dado que los mayores cambios se registraron en la región facial, la variación morfológica podría ser explicada como producto de la plasticidad fenotípica. Asimismo, no se encontró relación entre la variación morfológica y la distribución geográfica de las muestras.
\end{abstract}

Palabras Clave: Variación craneofacial, modificaciones culturales del cráneo, Quebrada de Humahuaca, Holoceno tardío.

Morphological variation of human populations of Quebrada de Humahuaca (Jujuy, Argentina)

\begin{abstract}
The aim of this paper was to analyze the craniofacial morphological variation in human samples showing no cultural modifications of the skull, belonging to populations that lived in the Quebrada de Humahuaca during the late Holocene. Shape and size alterations of the facial skeleton and skull base were studied, and the spatial distribution of morphological variables was evaluated. For this purpose, 114 skulls of adult men and women with slight or absent cultural modifications, from six archaeological sites in the middle section of the creek grade were selected. Forty-one anatomical points were registered in 3-D with a mechanical arm Microscribe G2X. To assess morphological variation an ANOVA as well as principal components and canonical variables. The association between morphology and geographic variation was assessed through a Procrustes analysis. Results indicate that craniofacial variation differs between facial skeleton and base. As the biggest change is found on the facial skeleton, morphological variation could be explained as a product of phenotypic plasticity. Also, no relationship between morphological variation and geographic distribution of the samples was found.
\end{abstract}

Keywords: Craniofacial variation, skull cultural modifications, Quebrada de Humahuaca, late Holocene.

La Quebrada de Humahuaca es un área caracterizada por grandes cambios en períodos temporales breves. Contrariamente a las hipótesis tradicionales que señalaban que los procesos de gran diversificación morfológica ocurrirían en escalas temporales y espaciales amplias, los trabajos recientes en biología evolutiva han mostrado que una gran diversificación morfológica puede ser encontrada en escalas espaciales y temporales acotadas (ver revisión en Carroll et al. 2007). A partir de una serie de modificaciones medioambientales conocidas como anomalía climática medieval (Fritz et al. 2004; Shimada et al. 1991; Thompson et al. 1985) se produjeron una serie de cambios en el área andina meridional aquí estudiada, en un rango temporal que

Recibido 16-09-2013. Recibido con correcciones 06-02-2014. Aceptado 07-03-2014 
abarca entre 1500 y 500 años AP (Nielsen 2001). Si bien no existen hasta el momento datos paleoclimáticos para la Quebrada de Humahuaca que permitan establecer de forma directa las condiciones ambientales para este momento, estudios realizados en otras regiones del Área Andina Meridional tales como depósitos paleolacustres de la cuenca del Titicaca y los glaciares de Quelccaya y Huascarán de la sierra peruana (Binford et al. 1997, Thompson et al. 1985), dan cuenta de una serie de fluctuaciones entre condiciones áridas y húmedas: 1) un período de precipitaciones abundantes entre hace 14001000 años AP, seguido de 2) un período de condiciones secas entre hace 1000 y 600 años AP, y finalmente 3) abundantes precipitaciones hace 600 años AP. En este momento se inicia un descenso de la temperatura media y se establecen condiciones más húmedas que en la actualidad (Thompson et al. 2000). Como producto de estos cambios paleoclimáticos se habría producido un reordenamiento de las poblaciones humanas durante el período conocido como Desarrollos Regionales (900-1430 dC, 1000-500 años AP). La población se asienta en la Quebrada troncal concentrándose en conglomerados de gran visibilidad y difícil acceso (Nielsen 2001), hay un auge del intercambio interregional por la acción de grupos caravaneros puneños-altiplánicos (Nielsen 2003), y aumenta la variación de prácticas socioculturales como las modificaciones culturales en los cráneos, presentándose el tipo tabular en sus dos variantes, erecta y oblicua (Seldes 2008/2010). Por otro lado, estudios bioarqueológicos han permitido afirmar para este momento, una mayor variación respecto a períodos anteriores en las frecuencias de indicadores de salud bucal, paleopatologías, indicadores de estilo de vida -tales como estrés nutricional/metabólico y estrés funcional (Gheggi 2012; Seldes 2006)- atribuidas a grupos que podrían estar realizando actividades diferentes y alimentándose de dietas distintas (Seldes 2012).

Los estudios morfológicos previos de las poblaciones humanas que habitaron la Quebrada, señalan una variación morfológica considerable para el limitado espacio geográfico (Bordach y Cocilovo 1991; Cocilovo et al. 2001; Varela et al. 2008). Según estos autores, esta variación morfológica presenta un patrón espacial que coincidiría con los datos etnohistóricos, planteando para momentos tardíos, dos grandes grupos viviendo en el área: los omaguacas en el norte, y los tilcaras en el sur (Cocilovo et al. 1999a; Cocilovo et al. 1999b; Varela et al. 1999). Estos autores atribuyen la magnitud de la diferenciación que encuentran en las variables morfológicas entre los distintos sitios arqueológicos, a procesos microevolutivos que habrían actuado en las poblaciones del área y al aporte migratorio de otros grupos provenientes de regiones limítrofes (Cocilovo et al. 1999b; Varela et al. 1999; Cocilovo et al. 2001). De esta manera, consideran que la distribución de los grupos habría estado basada en la divergencia genética de las poblaciones producida por el aislamiento espacial
(Varela et al. 2008; Varela et al. 2012). En este sentido, el asentamiento de grupos de distinta procedencia, principalmente de la Puna, Bolivia, Selvas Occidentales y de la subárea Valliserrana explicaría la gran variación morfológica que caracteriza a las poblaciones de la Quebrada (Varela et al. 2004). Estos investigadores pusieron a prueba, mediante un conjunto de análisis, la acción de diferentes factores evolutivos para explicar la divergencia morfológica de las poblaciones analizadas, concluyendo que la acción de la deriva balanceada por el flujo génico, habrían sido los principales procesos que operaron en el pasado en estas poblaciones (Cocilovo et al. 2009; Varela et al. 2008; Varela et al. 2012). Cabe destacar que estos estudios fueron realizados incluyendo a individuos que presentaban modificaciones culturales en los análisis, ya que estos investigadores consideran que la variación morfológica como producto de las modificaciones culturales es mínima (Cocilovo et al. 1999b; Cocilovo et al. 2001), pese a que se ha planteado que las modificaciones culturales del cráneo presentan un patrón geográfico que introduce variación adicional a la variación biológica de las muestras (Pérez 2007; Pérez et al. 2009).

Por otro lado, numerosos estudios han señalado que distintas regiones del cráneo presentan niveles disímiles de variabilidad con respecto a su respuesta a factores ambientales y/o neutrales. La región facial, especialmente el aparato masticatorio, debido a su extenso período de desarrollo (i.e. alcanza su tamaño y forma adulta final relativamente tarde en la ontogenia) y las altas demandas funcionales a las que está sujeta (i.e. cargas masticatorias por constituir el lugar de inserción muscular) presentaría una fuerte influencia de factores ambientales como la dieta y el clima (Hylander 1977; Skelton y McHenry 1992, Lieberman et al. 2004, Sardi et al. 2005; Harvati y Weaver 2006; Pérez et al. 2011). La plasticidad fenotípica puede generar en esta región craneana cambios morfológicos rápidos a nivel interpoblacional en períodos temporales breves (unas pocas generaciones; Carroll et al. 2007; Pérez y Monteiro 2009). Por otro lado, diversos estudios indican que la base del cráneo por sus características funcionales (i.e. constituye la estructura de soporte del cerebro y paso de nervios y vasos fundamentales para la vida) y tiempo de desarrollo (i.e. alcanza su tamaño y forma adulta en momentos relativamente tempranos en la ontogenia), presenta un comportamiento relativamente más independiente con respecto a la variación ambiental (Cheverud 1995; Lieberman et al. 2000; Relethford 1994; Roseman 2004). Los procesos microevolutivos (deriva, flujo génico) que operan durante la divergencia evolutiva de poblaciones localizadas en contextos ambientales particulares serían los principales factores que actúan sobre la variación morfológica de esta región craneana (Relethford 1994; Pérez y Monteiro 2009).

Por lo anteriormente expuesto, el objetivo del presente trabajo fue analizar la variación morfológica craneofacial 
en muestras humanas que no presenten modificaciones culturales del cráneo, y hayan habitado la Quebrada de Humahuaca durante el Holoceno tardío [período que comprende los últimos 1500 años de ocupación, que se corresponden con el Período de Desarrollos Regionales $(900-1430 \mathrm{dC})$ e Inka $(1430-1536$ dC)]. Se estudió la morfología del esqueleto facial y base craneana, excluyendo a la bóveda craneana de los análisis, para comparar la variación biológica de estas dos regiones craneanas sin introducir información de prácticas culturales en los análisis. Particularmente, en el presente trabajo se evaluó: 1) la variación morfológica en forma y en tamaño del esqueleto facial y base craneana, para indagar acerca de la acción diferencial de distintos procesos evolutivos sobre la variación morfológica de estas poblaciones, y 2) la asociación entre la variación morfológica y la variación espacial, para examinar si las poblaciones de la Quebrada se encontraban distribuidas siguiendo un patrón geográfico.

En función de estos objetivos se derivan las siguientes hipótesis de trabajo:

1) Si predomina la variación morfológica en la base craneana, tal como plantearon trabajos previos, la deriva y/o migración son los principales factores que permiten explicar la variación de las poblaciones de la Quebrada. Por el contrario, si la variación del esqueleto facial es mayor, la plasticidad fenotípica habría tenido un rol más importante en la diversificación morfológica de estas poblaciones. Este punto será evaluado a través del análisis de la variación en tamaño craneano y de forma.

2) Si existe un patrón geográfico en la variación morfológica de las muestras de los sitios de la Quebrada, tal como plantearon trabajos previos, las poblaciones habrían estado distribuidas en dos grandes grupos diferenciados en un sentido N-S para momentos tardíos. Por el contrario, si la variación morfológica no se distribuye de acuerdo a un patrón geográfico, las poblaciones habrían presentado una distribución más compleja que la planteada previamente. Este punto será evaluado a través de un análisis de Procrustes que permite analizar la asociación entre la variación morfológica y la espacial.

\section{Materiales y Métodos}

\section{Muestras}

Las muestras analizadas en el presente trabajo provienen de la Quebrada de Humahuaca, área correspondiente a la cuenca hidrográfica del Río Grande de Humahuaca, ubicada por encima de los 2000 m.s.n.m. La misma se encuentra ubicada en el sector central de la provincia de Jujuy y constituye un estrecho valle árido que tiene un recorrido N-S de casi $100 \mathrm{~km}$. Enclavada en la Cordillera Oriental, su límite occidental está formado por las Sierras de Aguilar, Alta y de Chañi, que la apartan de la Puna, mientras que su confín oriental se encuentra en las Serranías de Zenta, Hornocal y Tilcara, que la separan de la región de las yungas (Nielsen 2001). El accidentado relieve que caracteriza a la región y su incidencia sobre la temperatura, las precipitaciones y el desarrollo de suelos, resulta en un mosaico ecológico muy heterogéneo, en el que se yuxtaponen áreas con aptitudes diversas para el aprovechamiento humano.

Los cráneos aquí analizados se encuentran alojados en el Depósito de Antropología del Museo Etnográfico "J.B. Ambrosetti" de la facultad de Filosofía y Letras de la Universidad de Buenos Aires. Los materiales disponibles fueron excavados por distintos investigadores desde principios del siglo $X X$ en el marco de las $V$ a XXIV Expediciones de la Facultad de Filosofía y Letras de la Universidad de Buenos Aires. Dichos materiales han sido asignados al período de Desarrollos Regionales

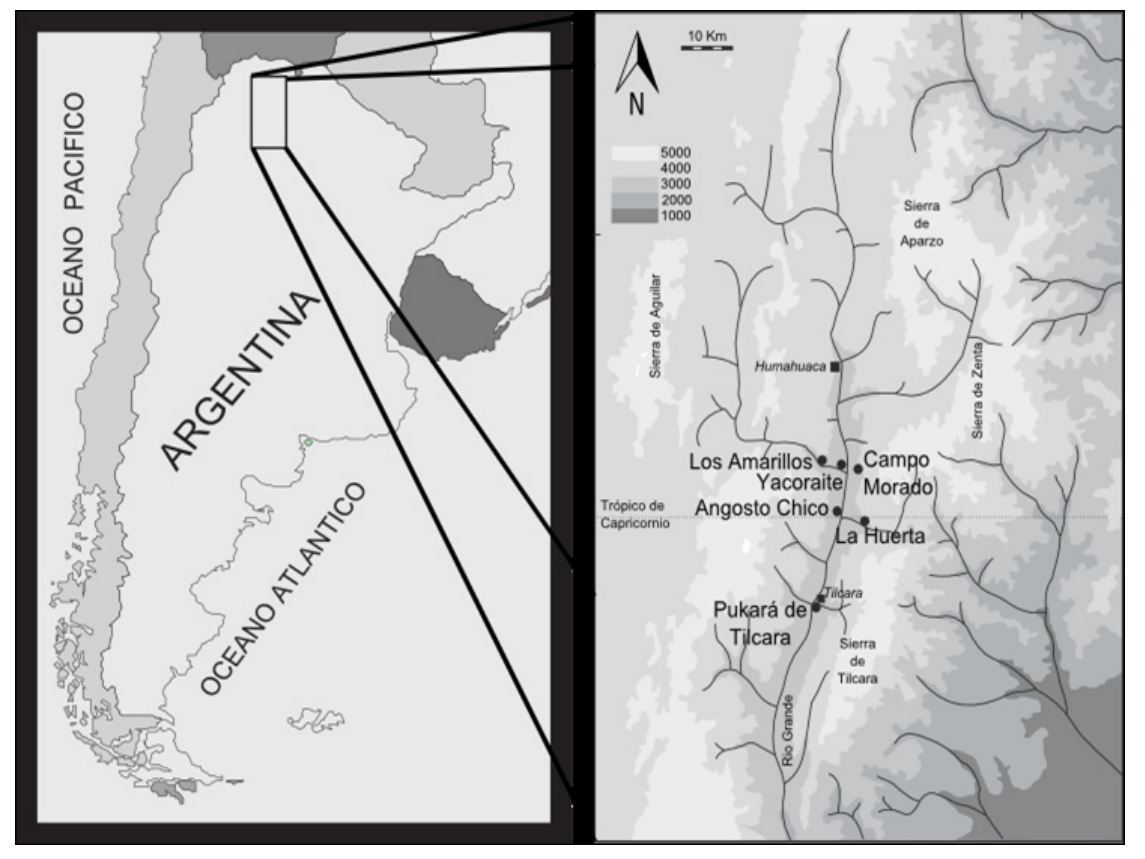

Figura 1. Mapa exhibiendo la localización geográfica de los sitios arqueológicos estudiados a lo largo de la Quebrada de Humahuaca, Provincia de Jujuy.

Figure 1. Map showing the geographical location of the archaeological sites studied along the Quebrada de Humahuaca, Province of Jujuy. 
I (900-1200 AD) y II (1200-1430 AD), ya que existen fechados radiocarbónicos que señalan la ocupación de esos sitios a partir de ese momento (Tabla 1). Si bien no se dispone de fechados radiocarbónicos para el sitio Yacoraite, el mismo ha sido atribuido en base a los materiales arqueológicos hallados al Período de Desarrollo Regionales que pertenece al Holoceno tardío final (Merlo et al. 2005). Los sitios Tilcara y Los Amarillos han sido considerados asentamientos de trazado concentrado, verdaderos conglomerados que sirvieron como sitios de habitación permanente (Nielsen 2001). Campo Morado, La Huerta y Yacoraite han sido considerados también conglomerados aunque de menor envergadura que los dos primeros. Por otro lado, Angosto Chico es considerado un asentamiento de baja densidad edilicia construido sobre una ladera nivelada, y a diferencia de los otros, ha tenido lapsos de ocupación más breve (Nielsen y Rivolta 1997).

El $n$ muestral a partir del cual se realizarán los análisis de morfometría geométrica quedó conformado por 114 individuos adultos de ambos sexos (Angosto Chico $\mathrm{n}=11$, 4 femeninos, 5 masculinos, 2 indeterminados;
Campo Morado $\mathrm{n}=18,7$ femeninos, 9 masculinos, 2 indeterminados; La Huerta $n=17,6$ femeninos, 8 masculinos, 3 indeterminados; Los Amarillos $n=21$, 8 femeninos, 9 masculinos, 4 indeterminados; Tilcara $n=30,12$ femeninos, 15 masculinos, 3 indeterminados; Yacoraite $n=17,6$ femeninos, 7 masculinos, 4 indeterminados) provenientes de seis sitios arqueológicos ubicados en el sector medio de la Quebrada de Humahuaca (Figura 1).

\section{Análisis preliminares}

Determinación de edad y sexo. Las determinaciones de sexo y edad se realizaron utilizando los procedimientos anatómicos estándares descritos por Buikstra y Ubelaker (1994). Dado que las muestras pertenecen a colecciones de museo, la mayoría de los individuos estuvieron representados sólo por cráneos, y por lo tanto las determinaciones se realizaron a partir de los rasgos craneales. La determinación de la edad se basó en la inspección del cierre de la sutura esfeno-basilar y la erupción del $\mathrm{M}^{3}$ (Buikstra y Ubelaker 1994). Los individuos fueron asignados a una de dos categorías,

\begin{tabular}{|c|c|c|c|c|}
\hline Sitio & $\mathrm{N} *$ Laboratorio & $\begin{array}{l}\text { Fechado/ } \\
\text { Cronología }\end{array}$ & $\begin{array}{l}\text { Fechado calibrado } \\
2 \text { sigmas }\end{array}$ & Referencia \\
\hline Angosto Chico & LP1990 & $450 \pm 60$ & $1320-1640$ & Rivolta et al 2010 \\
\hline Campo Morado & UGAM S03258 & $\begin{array}{l}\text { Periodo Desarrollos } \\
\text { Regionales/Inka }\end{array}$ & $1290-1330$ & $\begin{array}{l}\text { Palma 1997/98; } \\
\text { Fernández Do Rio } 2009\end{array}$ \\
\hline Campo Morado & UGAM S03257 & $\begin{array}{l}\text { Periodo Desarrollos } \\
\text { Regionales/Inka }\end{array}$ & $1250-1290$ & $\begin{array}{l}\text { Palma 1997/98; } \\
\text { Fernández Do Rio } 2009\end{array}$ \\
\hline Campo Morado & UGAM S 03256 & $\begin{array}{l}\text { Periodo Desarrollos } \\
\text { Regionales/Inka }\end{array}$ & $1260-1300$ & $\begin{array}{l}\text { Palma 1997/98; } \\
\text { Fernández Do Rio } 2009\end{array}$ \\
\hline Campo Morado & LP1868 & $\begin{array}{l}\text { Periodo Desarrollos } \\
\text { Regionales/Inka }\end{array}$ & $1302-1370$ & $\begin{array}{l}\text { Palma 1997/98; } \\
\text { Fernández Do Rio } 2009\end{array}$ \\
\hline Campo Morado & LP1838 & $\begin{array}{l}\text { Periodo Desarrollos } \\
\text { Regionales/Inka }\end{array}$ & $1522-1574$ & $\begin{array}{l}\text { Palma 1997/98; } \\
\text { Fernández Do Rio } 2009\end{array}$ \\
\hline Los Amarillos & AA12137 & $915 \pm 85$ & $1010-1290$ & Nielsen 1996 \\
\hline Los Amarillos & LP 659 & $920 \pm 50$ & $1030-1270$ & Nielsen 1996 \\
\hline Los Amarillos & AA13670 & $891 \pm 50$ & $1040-1280$ & Nielsen 1996 \\
\hline Los Amarillos & LP 669 & $780 \pm 70$ & $1059-1382$ & Nielsen 1997 \\
\hline Los Amarillos & AA 16239 & $620 \pm 49$ & $1284-1417$ & Nielsen 1997 \\
\hline Los Amarillos & AA 12135 & $590 \pm 55$ & $1289-1436$ & Nielsen 1997 \\
\hline Los Amarillos & A9602 & $630 \pm 45$ & $1290-1430$ & Nielsen 2001 \\
\hline Los Amarillos & A9603 & $520 \pm 40$ & $1326-1444$ & Nielsen 2001 \\
\hline Los Amarillos & AA12136 & $450 \pm 50$ & $1440-1638$ & Nielsen 1997 \\
\hline La Huerta & LP 165 & $150 \pm 80$ & $688-1020$ & Raffino y Alvis 1993 \\
\hline La Huerta & LP 700 & $660 \pm 40$ & $1274-1397$ & Raffino y Alvis 1993 \\
\hline La Huerta & LP 389 & $740 \pm 110$ & $1041-1412$ & Raffino y Alvis 1993 \\
\hline La Huerta & LP 335 & $680 \pm 90$ & $1174-1429$ & Palma 1998 \\
\hline La Huerta & AC1069 & $540 \pm 90$ & $1284-1609$ & Raffino y Alvis 1993 \\
\hline La Huerta & AC960 & $480 \pm 100$ & $1295-1642$ & Raffino y Alvis 1993 \\
\hline La Huerta & & $480 \pm 100$ & 1443 & Palma 1998 \\
\hline Pukara de Tilcara & LP 466 & $1160 \pm 70$ & $710-1050$ & Tarrago y Albeck 1997 \\
\hline Pukara de Tilcara & LP247 & $800 \pm 40$ & $1200-1380$ & Tarrago y Albeck 1997 \\
\hline Pukara de Tilcara & LP544 & $770 \pm 60$ & $1200-1400$ & Tarrago y Albeck 1997 \\
\hline
\end{tabular}

Tabla 1. Estimaciones cronológicas mediante ${ }^{14} \mathrm{C}$ de los sitios analizados.

Table 1 Chronological ${ }^{14} \mathrm{C}$ estimations of the analyzed sites. 
subadultos y adultos, considerando como adultos a aquellos individuos que tenían el $\mathrm{M}^{3}$ ya erupcionado y la sutura esfenobasilar ya cerrada. Se descartaron a los individuos subadultos, incluyendo sólo a los adultos en los análisis. La determinación de sexo se realizó macroscópicamente inspeccionando la glabela, malar, frontal, proceso mastoides, prominencia mentoniana y cresta nucal. Se seleccionaron estas estructuras debido a que presentan altos niveles de conservación en los contextos arqueológicos (Peterson y Dechow 2003) y porque un gran número de estudios previos sugieren que las mismas presentan un alto grado de dimorfismo sexual (Buikstra y Ubelaker 1994; González et al. 2011). Para la determinación del sexo se tomaron las propuestas de Buikstra y Ubelaker (1994), utilizando una escala del 1 al 5; con el 1 representando características gráciles típicas de cráneos de sexo femenino y el 5 indicando las características típicamente masculinas, aumentando progresivamente la pronunciación de cada variable; el 3 estaría indicando un tipo intermedio clasificado como de sexo indeterminado. La determinación del sexo en cada uno de los cráneos se realizó teniendo en cuenta todas las estructuras previamente mencionadas, y se clasificaron a los individuos en femeninos, masculinos e indeterminados.

Modificaciones culturales del cráneo. La costumbre de deformar los cráneos a los recién nacidos fue una práctica general de la que participaron muchos pueblos en la antigüedad y que abarcó casi todos los continentes y regiones, incluida la Quebrada de Humahuaca (Boada Rivas 1995). Cuando se realizaban estas prácticas de manera intencional, consistía en el proceso de cubrir parcialmente la cabeza del recién nacido con algún tipo de material que oficiara de venda y/o tablillas con el fin de producir modificaciones en la estructura morfológica del cráneo (Imbelloni 1924/25). Las modificaciones realizadas de manera no intencional resultaban del contacto del cráneo del infante con la madera de la cuna que la madre cargaba en su espalda para acarrearlo. A principios del siglo pasado, Imbelloni (1924/25) publicó la primera clasificación sistemática de las deformaciones craneanas realizada a partir de una muestra de cráneos procedentes de Perú, Bolivia y Argentina. En base a los aparatos deformadores que habrían sido utilizados, clasificó a las deformaciones como "Anulares" aquellas realizadas a través de vendas, y a las que utilizaban tablillas como "Tabulares", que a su vez subdividió en "Tabular Oblicua" y "Tabular Erecta" por la forma del occipital que se generaba como resultado. Posteriormente, Dembo e Imbelloni (1938) y Dembo y Vivante (1945) ampliaron esta clasificación incorporando entre las circulares a las variantes erecta y oblicua.

Trabajos previos plantean que las modificaciones culturales realizadas en cráneos pueden producir diferencias significativas en la morfología del esqueleto facial y la base craneana (Anton 1989; Cheverud et al. 1992), si bien esto no es válido en todos los casos, como por ejemplo en las poblaciones patagónicas (Sardi y Pucciarelli 2001; Pérez 2006). Teniendo en cuenta este supuesto, se descartaron para el presente estudio aquellos individuos que presentaron modificaciones en el cráneo como producto de prácticas culturales, con el fin de analizar solamente la variación biológica de la muestra. Para esto, se llevó a cabo un procedimiento mediante el cual se fue filtrando la variación morfológica asociada a dichas prácticas culturales, en tres pasos: (1) inspección visual macroscópica, (2) análisis morfométrico, (3) eliminación de los puntos de la bóveda de los análisis.

En primer lugar se realizó una inspección visual macroscópica (1) siguiendo las previamente citadas clasificaciones tipológicas. Se observaron todos los cráneos identificando si tenían modificaciones culturales del cráneo que fueron clasificadas según la tipología de Imbelloni (1924/25). Esto permitió detectar cráneos con modificaciones culturales de tipo tabular erecta, tabular oblicua, circular erecta y circular oblicua. Estos individuos fueron descartados y no se incluyeron en los análisis posteriores.

Luego se realizó una segunda inspección para evaluar la presencia de modificaciones culturales del cráneo mediante un análisis morfométrico (2), en aquellos individuos para los cuales no se pudo afirmar con certeza la presencia de estas modificaciones mediante la inspección macroscópica previa. En este sentido, se llevó a cabo un procedimiento analizando la forma del contorno de la bóveda a los fines de establecer con certeza la presencia de modificaciones culturales leves en la muestra medida (Pérez 2007; Pérez et al. 2009). Para esto se colocaron una serie de 16 puntos (5 landmarks y 11 semilandmarks) a lo largo de la línea sagital del cráneo. Se realizaron análisis de forma mediante el programa Morphologika 2.5 (O'Higgins and Jones, 2009). A partir de la observación de los cráneos en norma lateral se fueron descartando aquellos cráneos para los cuales macroscópicamente no se pudo afirmar con seguridad la presencia de alteraciones culturales, y que con esta metodología si presentaron modificaciones culturales.

Finalmente, dado que la muestra se caracteriza por una alta frecuencia de individuos con modificaciones culturales del cráneo, se decidió excluir a la bóveda craneana de los análisis posteriores (3), analizando sólo los puntos de la base craneana y del esqueleto facial. Del total de 218 cráneos de individuos adultos analizados en un principio, se seleccionaron un total de 114 cráneos sin modificaciones culturales del cráneo para continuar con los análisis morfométricos.

\section{Análisis Morfométricos}

Puntos registrados. El relevamiento de los puntos anatómicos del cráneo fue realizado por una de las 
autoras (LPM) para reducir el error interobservador. Se relevaron un total de 41 puntos anatómicos en 3D con un brazo mecánico Microscribe G2X describiendo el esqueleto facial y la base craneana (Tabla 2, Figura 2). En el esqueleto facial se registraron 30 puntos (21 landmarks y 9 semilandmarks), mientras que en la base craneana 11 landmarks. Los landmarks son puntos ubicados en la unión entre dos huesos mientras que los semilandmarks son puntos que se encuentran a los largo de contornos. Los landmarks fueron tomados a partir de las definiciones previas de Howells (1973) y de Buikstra y Ubelaker (1994), mientras que los semilandmarks fueron definidos para el presente trabajo. Los semilandmarks fueron ubicados describiendo los contornos de la órbita, los huesos frontal, temporal y la porción inferior del hueso cigomático.

Métodos para obtener variables de forma y tamaño. Se ajustaron mediante el método de Superposición Procrustes Generalizado los 41 puntos previamente registrados, para obtener las variables de forma. Este método alinea las configuraciones de puntos eliminando la información sobre el tamaño, posición y orientación original de las coordenadas. Estos análisis fueron realizados con el programa MorphoJ (Klingenberg 2011). Adicionalmente, se utilizó el criterio mínimo de Procrustes para deslizar los semilandmarks (Gunz et al. 2005) a partir de una serie de rutinas en $R$ mediante el paquete GeoMorph (Adams y Otarola-Castillo 2013). El tamaño fue definido a partir del tamaño centroide (TC) de manera independiente para el esqueleto facial y la base craneana. El tamaño centroide fue calculado a partir de la raíz cuadrada del resultante de la suma de las distancias cuadradas desde cada coordenada al centroide de la configuración (Bookstein 1991; Mitteroecker y Gunz 2009).

\section{Métodos estadísticos multivariados empleados}

Análisis del Tamaño. La variación del TC del esqueleto facial y la base craneana es presentada mediante gráficos de caja, que permiten comparar el rango de variación y la media en cada una de las seis muestras. Asimismo, se realizó un análisis de varianza de un factor (ANOVA) para evaluar si existen diferencias en el tamaño craneano entre las muestras. La hipótesis que se pone a prueba en el ANOVA de un factor es si las medias poblacionales del tamaño del esqueleto facial y de la base craneana son similares entre las muestras. Si las medias son similares, no hay una diferencia significativa entre las mismas y los grupos no difieren en cuanto a tamaño. Por el contrario, si las medias presentan diferencias significativas, el tamaño craneano difiere entre los grupos.

Análisis de la Forma. Se realizaron análisis de componentes principales (ACP) para reducir la dimensionalidad de las variables al estudiar la variación en forma del esqueleto facial y la base craneana, y para

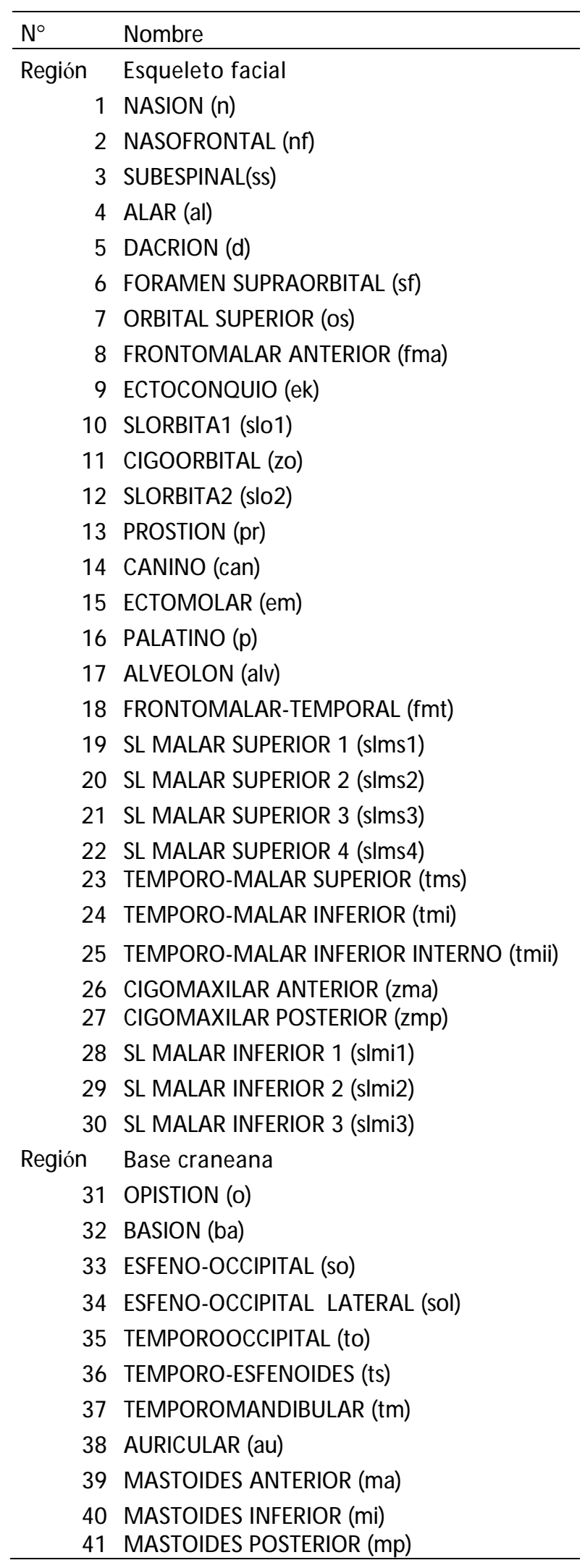

Tabla 2. Totalidad de landmarks y semilandmarks registrados en el presente trabajo con sus correspondientes abreviaturas.

Table 2 Complete list of landmarks and semilandmarks registered in this work including their abbreviations. 

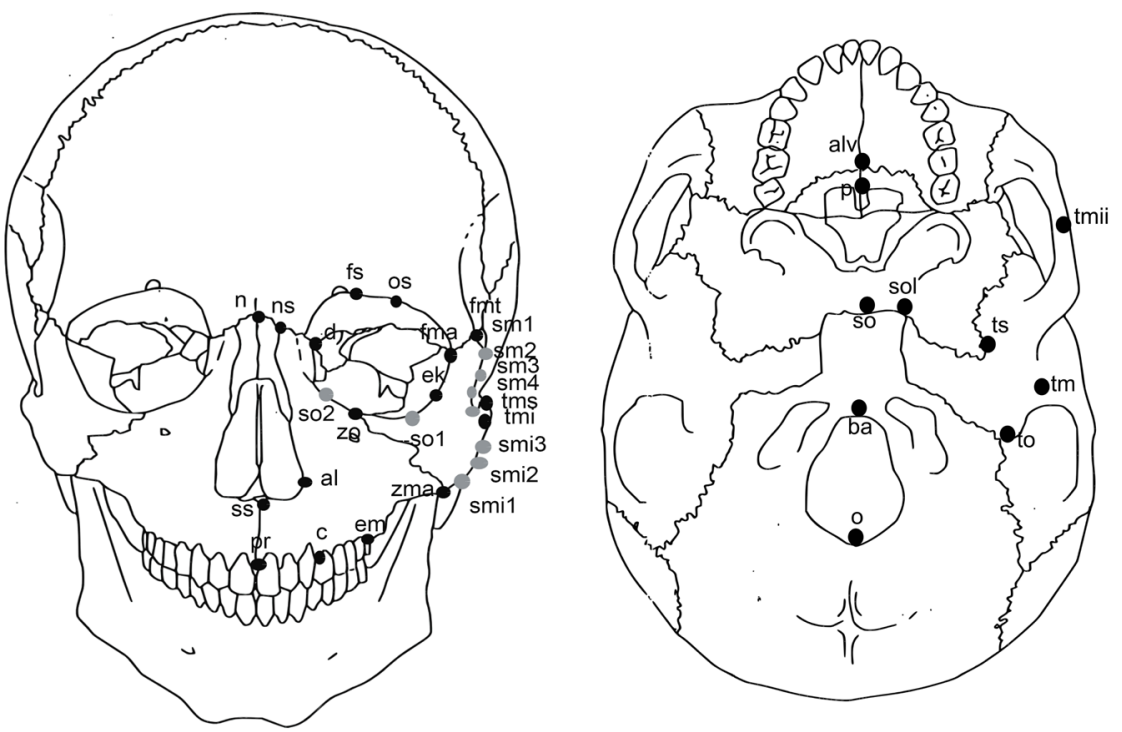

Figura 2. Landmarks y Semilandmarks registrados en el presente estudio por región craneana: a) esqueleto facial y b) base craneana.

Figure 2 Landmarks and Semilandmarks registered in this study by cranial region: a) face, and b) cranial base. encontrar los ejes de máxima variación de la muestra. A continuación se realizó, con los componentes principales que resumieron el $80 \%$ de la variación de la muestra, un análisis de variables canónicas (AVC). Este análisis permite encontrar la combinación lineal de las variables que mejor diferencian a los grupos entre sí. Se presentan los resultados del Lambda de Wilks que permiten valorar la significación estadística de las variables canónicas obtenidas. El estadístico Lambda de Wilks mide las desviaciones que se producen dentro de cada grupo respecto a las desviaciones totales sin distinción de grupos. Si su valor es pequeño (próximo a 0), la variabilidad total será debida a las diferencias entre grupos $y$, con ello, las variables con un Lambda de Wilks pequeño serán las que más diferencien a los grupos. Si por el contrario, su valor se aproxima a 1, los grupos se encuentran mezclados y, por ello, las variables independientes con un Lambda grande carecen de capacidad discriminante. Se grafica el centroide de la distribución por muestra a lo largo de los dos primeros componentes principales y las dos primeras variables canónicas. También se presenta el wireframe del esqueleto facial y el de la base craneana, para exhibir las principales tendencias de cambio de forma a lo largo del componente principal 1 , del extremo positivo (0.1) al negativo (-0.1).

Análisis espacial. La asociación entre las variables morfológicas y el espacio geográfico fue evaluada a través de un análisis de Procrustes. Este procedimiento que minimiza la sumatoria de las diferencias de cuadrados entre dos o más configuraciones (matrices de datos) en un espacio euclidiano multivariado. Hay varias estrategias para el análisis de Procrustes, pero el enfoque más usado es la superposición de mínimos cuadrados de una configuración $Y$ (n filas o las observaciones de $k$ columnas o variables) a una configuración de referencia $X\left(n^{*} k\right)$. Es una herramienta potente para detectar asociación entre matrices (Peres-Neto y Jackson 2001).
Se realizó esta prueba para examinar si la variación morfológica presenta un patrón geográfico. El espacio geográfico fue representado por las coordenadas geográficas decimales de los sitios (latitud y longitud), y la variación en forma y tamaño de la muestras fueron representadas por: el CP1 del esqueleto facial, el CP1 de la base craneana, el TC del esqueleto facial y el TC de la base craneana. Los resultados y la significancia estadística de esta prueba equivalen a una correlación de Pearson y serán interpretados como tal.

La totalidad de los análisis estadísticos fueron realizados en MorphoJ (Klingenberg 2011) y R (R Core Team 2012).

\section{Resultados}

\section{Tamaño}

Los resultados de tamaño se pueden apreciar a partir de los gráficos de caja (Figura 3), donde se ven las diferencias de TC del esqueleto facial y la base craneana por sitio arqueológico. En términos generales se observan las mismas tendencias, por lo que se describirá a continuación el gráfico del esqueleto facial (Figura 3a). Sin embargo, cabe destacar que el esqueleto facial presentó mayor variación que la base craneana, es decir si bien coincide el ordenamiento de los valores medios, la amplitud de valores fue mayor en el esqueleto facial, y por ende mayores las diferencias entre los valores mínimos y máximos. La muestra de Yacoraite presenta los mayores tamaños mientras que la muestra de Angosto Chico presenta los tamaños más pequeños. La muestra de La Huerta es la que presenta el rango más amplio de variación, mientras las de Yacoraite y Angosto Chico presentan los menores rangos de variación. En general, las muestras que presentan el esqueleto facial de mayor tamaño también presentan las bases craneanas más grandes. Las muestras que presentan el esqueleto facial de mayor tamaño son Yacoraite, La 


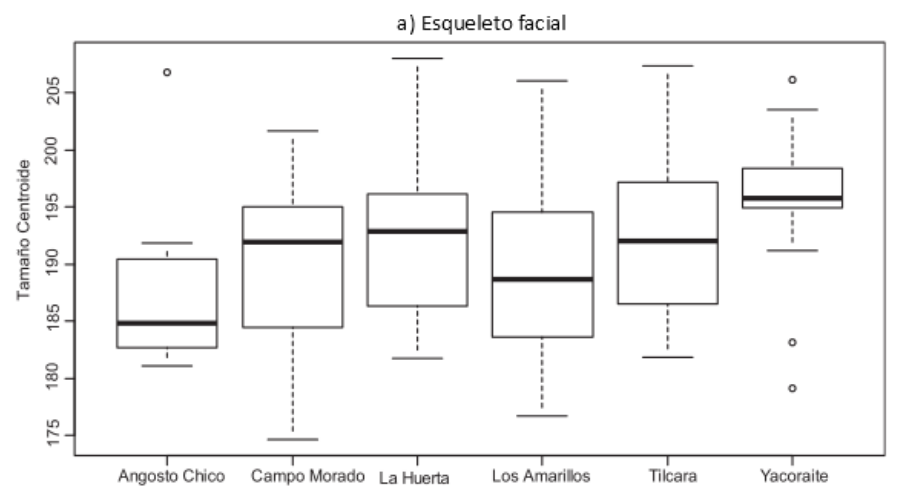

b) Base craneana

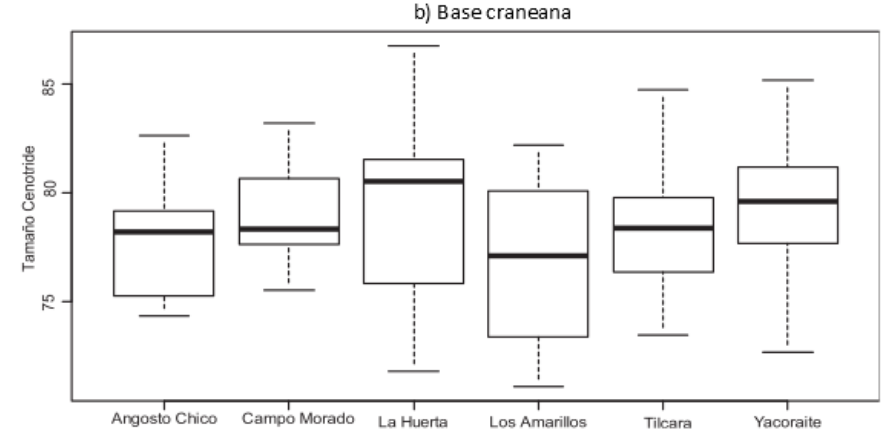

Figura 3. Gráficos de caja mostrando la variación en valores de TC por región craneana: a) esqueleto facial, b) base craneana.

Figure 3. Boxplots showing variation in CS (TC) values by cranial region: a) face, b) cranial base.

Huerta, Tilcara y Campo Morado, mientras Los Amarillos y Angosto Chico presentan el esqueleto facial más pequeño (Figura 3a). Las muestras que se encuentran en los extremos, Yacoraite que presenta el mayor tamaño y Angosto Chico el menor, presentan asimismo la menor amplitud de variación, mientras el resto de las muestras presentan gran variación para el tamaño del esqueleto facial. Cuando se observan los gráficos de caja de la base craneana (Figura 3b), se puede ver que las muestras de La Huerta y Yacoraite son las que presentan los mayores tamaños, mientras Los Amarillos, Campo Morado, Angosto Chico y Tilcara presentan los tamaños menores, siendo Los Amarillos la que presenta la base craneana más pequeña y La Huerta, la base craneana de mayor tamaño. En este caso, la muestra de Los Amarillos es la que presenta un rango más amplio de variación en cuanto al tamaño de la base craneana, y Campo Morado la de menor rango de variación.

Se realizó un ANOVA para evaluar las diferencias de tamaño medio entre las muestras analizadas (Tabla 3). Los resultados indican que no existen diferencias significativas entre el tamaño del esqueleto facial ni de la base craneana por sitio arqueológico. A pesar de esto, se puede observar que las diferencias en tamaño entre las muestras son levemente mayores cuando se considera el esqueleto facial, que cuando se considera la base craneana.

\begin{tabular}{lcc}
\hline & $\mathrm{F}$ & $\mathrm{p}$ \\
\hline TC esqueleto facial & 0.84 & 0.52 \\
TC base craneana & 0.48 & 0.78 \\
\hline
\end{tabular}

Tabla 3. Resultados del análisis de la varianza de un factor para comparar diferencias de tamaño craneano entre las muestras. TC corresponde a tamaño centroide.

Table 3. Analysis of variance results comparing differences in cranial size between samples. TC corresponds to the centroid size.

\section{Forma}

En los resultados de los análisis de componentes principales de forma (ACP) del esqueleto facial se pueden identificar tres conjuntos: Los Amarillos/ Tilcara, Yacoraite/Campo Morado/La Huerta y Angosto Chico. El CP1 separa las muestras de Los Amarillos y Tilcara, que se encuentran cercanas, de las restantes 4, mientras el CP2 separa la muestra de Angosto Chico de las otras 5 (Figura 4a). En la base craneana, la distribución es similar, pero las muestras no están tan marcadamente agrupadas como cuando se considera al esqueleto facial (Figura 4b). A partir de los CPs se realizó un análisis de variables canónicas (AVC) para el esqueleto facial y otro para la base craneana. Las dos primeras variables canónicas resumen más del $75 \%$ de la variación total de la muestra. Gráficamente se puede observar en el AVC del esqueleto facial (Figura 4c) que las muestras se agrupan a partir de la VC1 de manera tal que Tilcara y Los Amarillos se agrupan entre sí y se separan del resto. Por su parte, a lo largo de la VC2 las muestras se presentan como un continuo, con La Huerta y Tilcara en un extremo y Los Amarillos y Angosto Chico en el otro. En la base craneana (Figura 4d), la VC1 separa a las muestras de Tilcara y Los Amarillos de las otras 4; mientras la VC2 agrupa Angosto Chico con La Huerta, y las otras 4 muestras entre sí. Cuando se observan las distancias del esqueleto facial, las muestras más disímiles son las de La Huerta/Amarillos y Yacoraite/ Amarillos, mientras que las más cercanas son Amarillos/ Tilcara y Campo Morado/Yacoraite. Cuando se observan los estadísticos de estos análisis (Tabla 4), el valor del estadístico $\mathrm{F}$ de la base craneana es menor que el del esqueleto facial. Si bien ambos son estadísticamente significativos $(<0.02 \mathrm{y}<0.00)$, hay menor diferenciación entre los grupos cuando se considera la base craneana. Es decir existen mayores diferencias en el esqueleto facial entre los grupos. Asimismo, el valor de Lambda de Wilk's es más alto para la base craneana que para el esqueleto facial (Tabla 4). Estos estadísticos estarían indicando que las diferencias morfológicas entre los grupos son mayores entre el esqueleto facial que entre la base craneana. Si bien en ambos casos se aprecian diferencias estadísticamente significativas entre los grupos considerados, al considerar la base craneana, los 

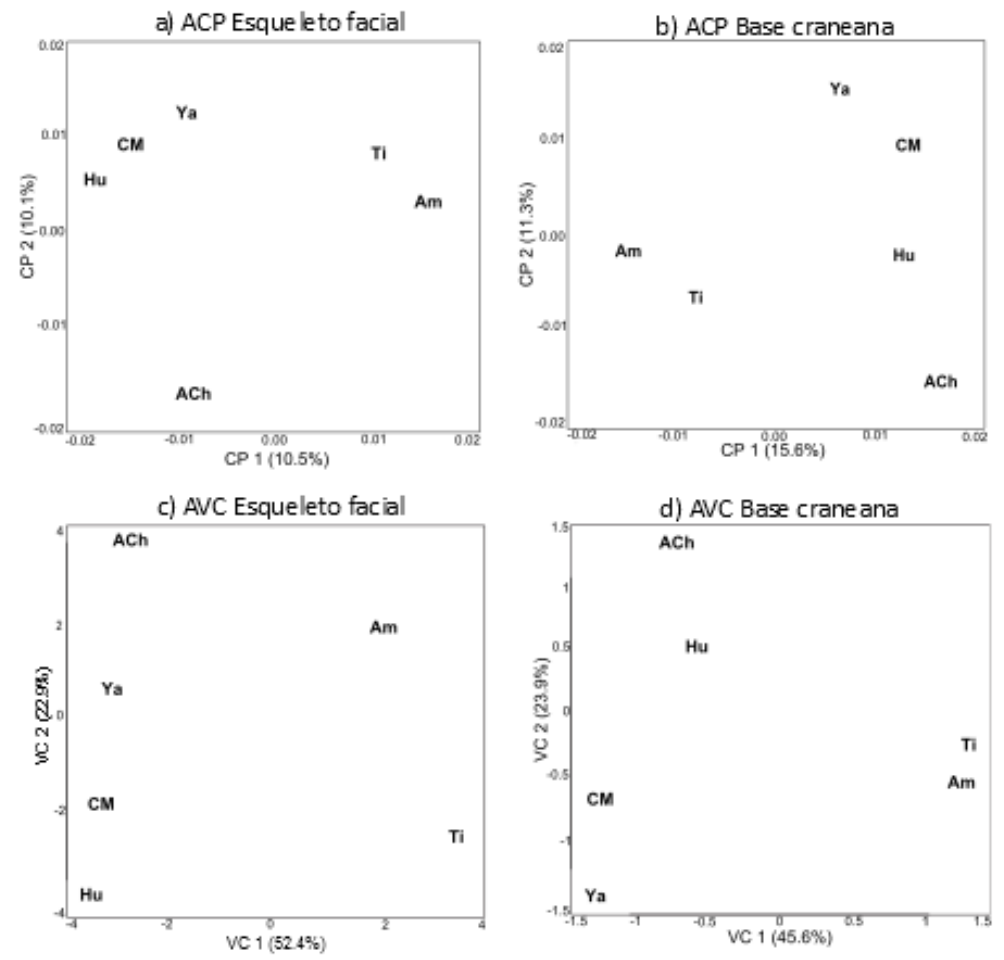

Figura 4. Resultados de la distribución de las 6 muestras por región craneana a lo largo de los dos primeros componentes principales de forma: a) esqueleto facial, $y$ b) base craneana y de las dos primeras variables canónicas: c) esqueleto facial, y d) base craneana.

Figure 4. Results of the 6 samples distribution by cranial region along the first two principal components: a) face and b) cranial base, and the two first canonical variables: c) face, and d) cranial base.

\begin{tabular}{cccc}
\hline & $\mathrm{F}$ & LWilk's & $\mathrm{p}$ \\
\hline Esqueleto facial & 2.55 & 0.03 & 0.00 \\
Base craneana & 1.74 & 0.45 & 0.02 \\
\hline
\end{tabular}

Tabla 4. Resultados del análisis de variables canónicas. El estadístico Lambda de Wilks mide las desviaciones que se producen dentro de cada muestra respecto a las desviaciones totales sin distinción de muestras.

Table 4. Results of canonical variable analysis. The statistic Wilk's Lambda measures the deviations that occur within each sample in relation to total deviations regardless of samples. grupos presentan más similitudes entre sí.

A continuación se presentan los wireframes (Figura 5), donde pueden verse los cambios en forma localizados en determinadas regiones del esqueleto facial y la base craneana. Los wireframes son un conjunto de líneas que conectan los landmarks y semilandmarks en un gráfico, facilitando la visualización de la configuración de puntos y los resultados. La forma media aparece como puntos huecos en gris claro representando los landmarks y semilandmarks, mientras que en los puntos sólidos en negro, se ven los cambios de forma que se corresponden con un aumento de 0.1/-0.1 unidades Procustes de distancia en la dirección del CP1. En el wireframe del esqueleto facial (Figura 5a) se puede observar que la principal variación a lo largo del CP1 se registra en la región del paladar, maxilar, órbita, nariz, y arco cigomático. En el extremo negativo del CP1, representado por las muestras de Yacoraite, Campo Morado, La Huerta y Angosto Chico puede verse que el paladar es más amplio, la órbita más circular, la nariz mas corta, el maxilar y arco cigomático más robustos. En general el esqueleto facial es más corto y ancho en el extremo negativo del CP1. Por otro lado, el extremo positivo del CP1, representado por las muestras de Tilcara y Los Amarillos, el paladar es más suave, la órbita más ovalada en sentido superior/inferior, la nariz más alta, mientras el maxilar y arco cigomático son más angulosos. En términos generales el esqueleto facial es más alargado y angosto en el extremo positivo del CP1. En el wireframe de la base craneana (Figura 5b) se pueden observar que los principales cambios se encuentran en la fosa mandibular, esfeno-occipital y temporo-occipital. En el extremo negativo del CP1, representado por las muestras de Tilcara y Los Amarillos, la fosa mandibular es más pequeña, el esfeno-occipital es más ancho y el temporo-occipital se ubica más alejado del plano sagital. En general en el extremo negativo del $C P 1$, representado por kas muestras de Yacoraite, Campo Morado, La Huerta y Angosto Chico, la base craneana es más corta en el plano sagital y se ensancha hacia el lateral. En el extremo positivo del CP1, la fosa mandibular es más pequeña, el esfeno-occipital es más angosto y el temporo-occipital se ubica más cerca del plano sagital. En términos generales, la base craneana es más alargada en el plano sagital y más angosta en el extremo positivo del CP1.

\section{Análisis espacial}

El análisis de Procrustes permite analizar si existe una asociación entre las variables morfológicas y el espacio geográfico. En la Tabla 5 se exhiben los resultados del análisis de Procrustes, los cuales indican que la variación morfológica observada no tiene un patrón geográfico, es decir la variación en forma y tamaño de las muestras analizadas varía independientemente del espacio y/o están asociadas a otros factores. Ninguno de los valores es significativo estadísticamente.

\section{Discusión}

Tal como fue planteado anteriormente, el propósito del presente trabajo fue analizar la variación morfológica craneofacial en muestras humanas que no presenten modificaciones culturales del cráneo, y hayan habitado la Quebrada de Humahuaca durante el Holoceno tardío. Particularmente, en el presente trabajo se evaluó: 1) 


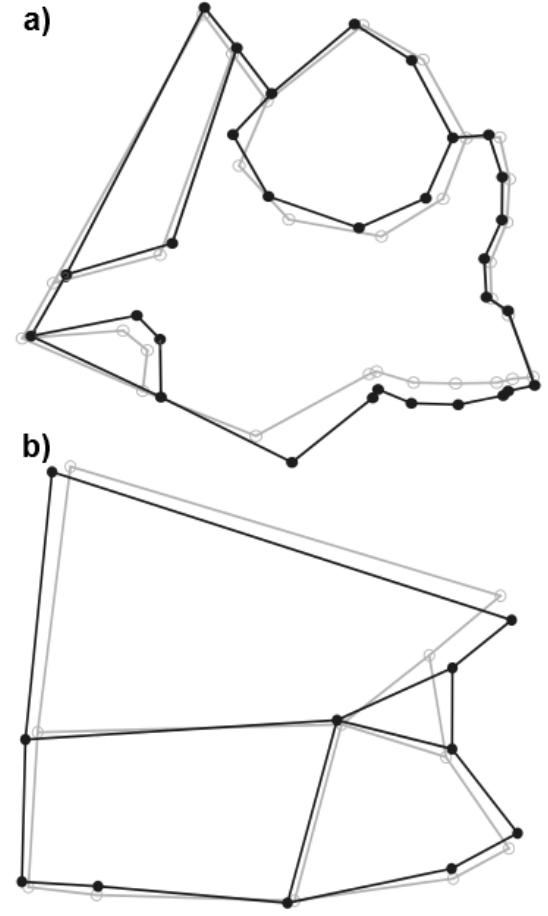

CP1-

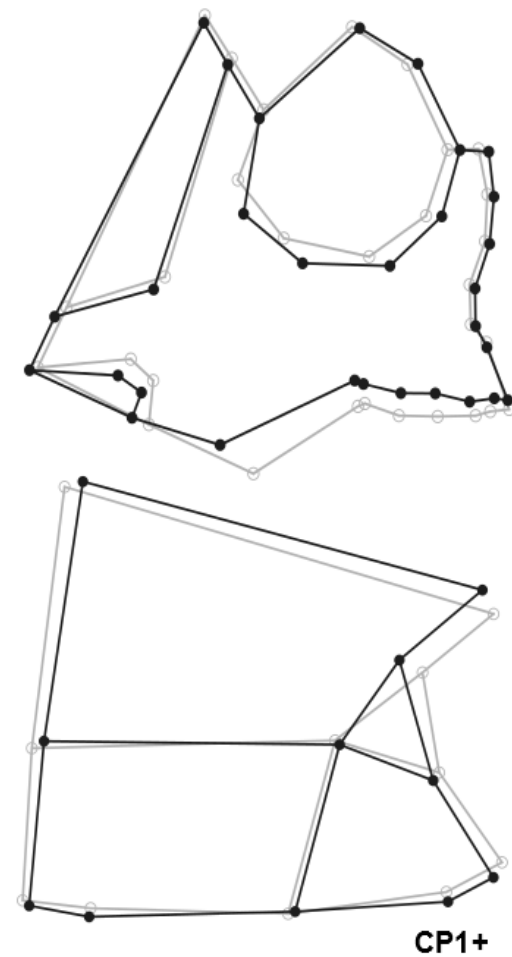

CP1+

Figura 5. Wireframes mostrando los principales cambios de forma a lo largo del CP1 por región craneana: a) esqueleto facial, y b) base craneana. Las imágenes en la izquierda representan el extremo negativo del CP1, mientras que las imágenes de la derecha representan el extremo positivo del mismo.

Figure 5 Wireframes showing major form changes over PC1 (CP1) by cranial region: a) face, b) cranial base. Images on the left represent the negative extreme of PC1 (CP1), while the images on the right represent the positive extreme.

la variación morfológica en forma y en tamaño del esqueleto facial y base craneana, para indagar acerca de la acción diferencial de distintos procesos evolutivos sobre la variación morfológica de estas poblaciones, y 2) la asociación entre la variación morfológica y la variación espacial, para examinar si las poblaciones de la Quebrada se encontraban distribuidas siguiendo un patrón geográfico.

Con respecto al primer punto, los resultados de los análisis morfométricos aquí realizados permiten afirmar la existencia de una considerable variación morfológica en la región, que se expresa diferencialmente en el esqueleto facial y en la base craneana. Este resultado coincide con los resultados alcanzados por estudios previos, donde análisis de morfometría craneana tradicional (Cocilovo et al. 1999b; Cocilovo et al. 2001) y estudios de variables craneanas no-métricas (Cocilovo et al. 2004), demostraron la existencia de una considerable variación morfológica dadas las reducidas dimensiones del área y el limitado intervalo cronológico de las muestras estudiadas (Bordach y Cocilovo 1991; Cocilovo et al. 2001; Varela et al. 2008; Mendisco et al. 2011). La variación morfológica aquí hallada, se encuentra presente en distinto grado en el esqueleto facial y en la base craneana. Dadas las diferencias en origen, crecimiento y desarrollo previamente

\begin{tabular}{lcc}
\hline & $\mathrm{R}$ & $\mathrm{p}$ \\
\hline CP1 Esqueleto facial & 0.2088 & 0.795 \\
CP1 Base craneana & 0.3332 & 0.521 \\
TC Esqueleto facial & 0.1032 & 0.917 \\
TC Base craneana & 0.3014 & 0.595 \\
\hline
\end{tabular}

Tabla 5. Resultados del análisis de Procrustes para evaluar la asociación entre variación geográfica y morfométrica entre las muestras. CP1 corresponde a componente principal 1, TC a tamaño centroide.

Table 5 Results of Procrustes analysis to assess the association between geographic and morphometric variation among samples. CP1 corresponds to principal component 1, TC a centroid size.

mencionadas de estas regiones craneofaciales, el distinto grado de variación morfológica en las mismas estaría indicando que tanto procesos aleatorios como factores ambientales actuaron diferencialmente sobre la morfología craneofacial. En el presente estudio se analizó la variación en el esqueleto facial y la base craneana independientemente, resultando la variación morfológica presente en el esqueleto facial considerablemente mayor que la de base craneana. Esto se observó tanto cuando se analizaron los cambios en forma como en tamaño del esqueleto facial, que siempre presentó mayor variación que la base craneana. Dicha variación está concentrada en las regiones del maxilar y arco cigomático, áreas que en el esqueleto facial están asociadas a la masticación. Esto estaría señalando que factores no aleatorios como la selección direccional y la plasticidad fenotípica hayan estado incidiendo sobre la variación morfológica craneofacial en mayor magnitud que factores de tipo aleatorio. La gran amplitud ecológica del área, que incluye una gran diversidad de recursos locales provenientes de distintos pisos ecológicos, sumado a los recursos provenientes de regiones aledañas como producto del tráfico caravanero (Nielsen 2007), habrían brindado una diversificación dietaria considerable que puede haber estado asociada a las variaciones en la morfología craneofacial observadas. Cabe destacar que en trabajos morfométricos previos se interpreta la variación encontrada como el producto del efectivo asentamiento de grupos provenientes de subáreas vecinas así como también de regiones más distantes tales como la Puna, Bolivia y las Selvas Occidentales (Cocilovo et al. 1999b; Varela et al. 2004). De acuerdo a estos autores, el flujo génico de grupos provenientes de otras regiones habría ampliado la variación preexistente en las poblaciones del área. Esto ha sido también planteado desde la evidencia arqueológica 
donde las semejanzas formales entre algunos aspectos de la cultura material de la Quebrada para el Período de Desarrollos Regionales I y la de Tiwanaku de Bolivia, han llevado a postular la existencia de algún tipo de contacto entre ambas, ya sea de forma directa o indirecta mediatizada por grupos del norte de Chile (Nielsen 2001). Sin embargo, los mencionados trabajos han abordado el estudio del cráneo como unidad, y dado que varios estudios han señalado que el patrón de variación general del cráneo se relaciona, principalmente, con factores neutrales o evolutivos (Relethford, 1994; Roseman, 2004), es esperable que arriben a dichas conclusiones.

Con respecto al segundo punto, a partir de los resultados del presente trabajo se puede afirmar que no existe asociación entre la variación morfológica y la distribución geográfica de las muestras de cráneos humanos en la Quebrada durante el Holoceno tardío. No sólo la correlación entre las variables morfológicas y el espacio es baja sino que los agrupamientos más recurrentes que aparecen en los resultados de los análisis aquí realizados no tienen ningún correlato geográfico (Tilcara/Los Amarillos, Campo Morado/Yacoraite y Angosto Chico/ La Huerta). Esto se diferencia de lo obtenido en trabajos previos donde los resultados presentaban una distribución de las muestras concordante con un patrón geográfico (Cocilovo et al. 1999a; Cocilovo et al. 1999b; Varela et al. 1999). Dichos trabajos plantean una dinámica poblacional para la Quebrada donde el sector norte habría mantenido contactos con la Puna, el sector sur con los Valles Calchaquíes y los valles orientales de Jujuy, estos dos últimos principalmente a través del la población del sector septentrional de la Quebrada (Garay de Fumagalli 1998; Garay de Fumagalli y Cremonte 1997; Gheggi 2012). La contrapartida etnohistórica de tal división territorial son los grupos Omaguacas que habitaron desde el Angosto de Perchel hasta Iturbe con centro de residencia en Los Amarillos y Yacoraite; y los Tilcaras que habitaron desde la Quebrada de Yucara hasta el río de Omaguaca (Sánchez y Sica 1991; Varela et al. 1999). Si bien dos de los tres pares de muestras que exhiben una mayor afinidad morfológica entre sí (Yacoraite/Campo Morado y Angosto Chico/La Huerta) presentan una cercanía espacial que permite explicar sus similitudes craneométricas como producto de un patrón geográfico, las muestras Tilcara/Los Amarillos (este último compartiendo esa posición con Yacoraite) se encuentran en los extremos sur y norte de la distribución de sitios del sector medio de la Quebrada. Ambos sitios son considerados por Nielsen (1989) como centros polinucleares complejos, es decir, habrían constituido grandes conglomerados con abundantes estructuras, ubicados en lugares altos con ventajas defensivas (Nielsen 2001). Por otro lado, sitios como Los Amarillos y Yacoraite que se encuentran a una estrecha distancia espacial, no poseen similitudes morfológicas craneofaciales, ya que Yacoraite se agrupa con Campo Morado mientras Los Amarillos con Tilcara como se comentó anteriormente. Es decir, otros factores distintos a los esperables por una estructuración geográfica del espacio (e.g. migración, deriva) estarían generando diferencias entre las muestras de la Quebrada para momentos tardíos.

En síntesis, los resultados aquí alcanzados: 1) la amplia variación morfológica principalmente del esqueleto facial, y 2) la inexistencia de un patrón geográfico que explique la variación morfológica, permiten plantear la prevalencia de factores ambientales sobre procesos evolutivos actuando sobre la variación morfológica de las poblaciones de la Quebrada de Humahuaca durante el Holoceno tardío. Existen considerables diferencias metodológicas y en las conclusiones alcanzadas entre el presente estudio y los trabajos previos en el área. Mientras que los estudios previos, realizados por Cocilovo y colaboradores (1999a; 1999b; 2001) y Varela y colaboradores (1999, 2008), analizan la variación morfológica craneofacial del cráneo como unidad, utilizan medidas antropológicas clásicas que describen la morfología del cráneo de manera general (i.e. altura basilo-bregmática) y local (i.e. ancho nasal), incluyen a la bóveda craneana en sus análisis y a individuos que presentaron modificaciones culturales del cráneo; en el presente trabajo se analizó la variación morfológica del esqueleto facial y base craneana independientemente, se utilizaron puntos en 3D mediante morfometría geométrica, se excluyó a la bóveda craneana y a los individuos con modificaciones culturales del cráneo de los análisis. Dentro del conjunto de diferencias metodológicas planteadas, se considera que la inclusión/ exclusión de la bóveda craneana e individuos con modificaciones culturales en los cráneos en los análisis, ha sido el criterio de mayor importancia, que podría estar generando las principales diferencias en los resultados y las conclusiones alcanzadas. Dichos estudios previos consideran que la variación morfológica como producto de las modificaciones culturales es mínima (Cocilovo et al. 1999b; Cocilovo et al. 2001), y aseveran que la distribución de dichas prácticas culturales no es aleatoria sino que están distribuidas según localidades (Cocilovo et al. 1999a). Asimismo, estudios posteriores en una escala mayor plantearon que existe para momentos tardíos un patrón de variación morfológica en las modificaciones culturales del cráneo coincidente con la distribución geográfica de las muestras (Pérez 2007; Pérez et al. 2009). En función de esto es posible afirmar que la variación morfológica descripta en trabajos previos esté reflejando la variación producto de modificaciones culturales más que la variación biológica de la morfología de las poblaciones del área. Esa variación de las modificaciones culturales puede estar encubriendo tal variación biológica. Por esta razón, en el presente trabajo se excluyeron los individuos que presentaban modificaciones culturales del cráneo (salvo algunos con modificaciones muy leves) y los puntos de la bóveda craneana, abordando la variación biológica de la morfología craneofacial de las poblaciones que habitaron la Quebrada de Humahuaca en el Holoceno tardío. Asimismo, el análisis del esqueleto facial y la base craneana por separado permitió ahondar en el estudio 
de la variación morfológica de estas poblaciones, y así indagar en los factores asociados a la variación morfológica presente.

La Plata, 18 de febrero de 2014

\section{Agradecimientos}

A Valeria Bernal e Iván Pérez por los valiosos comentarios que ayudaron a mejorar el trabajo. Las opiniones expresadas son de exclusiva responsabilidad de las autoras.

\section{Bibliografía}

Adams, D.C., E Otarola-Castillo. 2013. Geomorph: an $R$ package for the collection and analysis of geometric morphometric shape data. Methods in Ecology and Evolution 4: 393-399.

Anton, S.C. 1989. Intentional Cranial Vault Deformation and Induced Changes of the Cranial Base and Face. American Journal of Physical Anthropology 79: 253-267.

Binford, M.W., A.L. Kolata, M. Brenner, J.W. Janusek, M.T. Seddon, M. Abbot, J.H. Curtis. 1997. Climate variation and the Rise and Fall of an Andean Civilization. Quaternary Research 47: 235-248.

Boada Rivas, A.M. 1995. La deformación craneana como marcador de diferenciación social. Boletín del Museo del Oro 38-39: 135-147.

Bookstein, F.L. 1991. Morphometric tools for landmark data: Geometry and biology. Cambridge University Press, Nueva York.

Bordach, M.A., J.A. Cocilovo. 1991. Composición y estructura de la Población Prehistórica de la Quebrada de Humahuaca, Primera Aproximación. Antropología Biológica 1 (1): 15-32.

Buikstra, J.E., D.H. Ubelaker. 1994. Standards for data collection from human skeletal remains. Arkansas Archaeological Survey 44, Fayeteville.

Carroll, S.P., A.P. Hendry, D.N. Reznick y C.W. Fox. 2007. Evolution on ecological time-scales. Functional Ecology 21 : 387-393.

Cheverud, J. M. 1995. Morphological integration in the saddle-back tamarin (Saguinus fusciollis) cranium. American Naturalist 145: 63-89.

Cheverud, J.M., L.A.P. Kohn, L.W. Konigsberg y S.R. Leigh. 1992. Effects of the Fronto-Occipital Artificial Cranial Vault Modification on the Cranial Base and Face. American Journal of Physical Anthropology 88: 323-345.
Cocilovo, J., H.Varela, E.I. Baffi, S.Valdano y M.F. Torres. 1999a. Estructura y composición de la población antigua de la Quebrada de Humahuaca. Análisis exploratorio. Relaciones de la Sociedad Argentina de Antropología 24: 59-80. Buenos Aires.

Cocilovo, J., H.Varela, E.I. Baffi y S.Valdano. 1999 b. Estructura y composición de la población antigua de la Quebrada de Humahuaca. Análisis multivariado. Revista Argentina de Antropología Biológica 2 (1): 7-26.

Cocilovo, J.A., H.H. Varela y S.G. Valdano. 2001. Estructura de la población antigua de la Quebrada de Humahuaca. Berberian, E., A. Nielsen, editores, Historia Argentina Prehispánica, Tomo I, 265-287, Editorial Brujas, Córdoba.

Cocilovo, J.A., H.H. Varela, S. Quevedo, V. Standen, y M.A. Costa-Junqueira. 2004. La diferenciación geográfica de la población humana arcaica de la costa norte de Chile (50003000 AP) a partir del análisis estadístico de rasgos métricos y no métricos del cráneo. Revista Chilena de Historia Natural 77: 679-693.

Cocilovo, J.A., H.H. Varela y T.G.O’Brien. 2009. La divergencia genética entre poblaciones del área andina centro meridional evaluada mediante rasgos no métricos del cráneo. Revista Argentina de Antropología Biológica 11 (1): 43-59.

Dembo, A., J. Imbelloni. 1938. Deformaciones intencionales del cuerpo humano de carácter étnico. Editorial Humanior, Buenos Aires.

Dembo, A., A. Vivante. 1945. La moda de las deformaciones corporales. Editorial Las Dos Estrellas, Buenos Aires.

Fernandez Do Rio, S. 2009. Apropiación incaica de un lugar sagrado en la Quebrada de Humahuaca Jujuy, Argentina. Arqueología 15: 41 - 62.

Fritz, S., P.Baker, T. Lowenstien, G. Seltzer, C. Rigsby, G. Dwyer. P. Tapia, K. Arnold, T. Ku y S. Luo. 2004. Hydrologic variation during the last 170.000 years in the southern hemisphere tropics of South America. Quaternary Research 61: $95-104$.

Garay de Fumagalli, M. 1998. El Pucará de Volcán, Historia Ocupacional y Patrón de Instalación. Cremonte, M.B., editor, Los desarrollos locales y sus territorios: arqueología del Noa y Sur de Bolivia, 131-153, Universidad Nacional de Jujuy, Jujuy.

Garay de Fumagalli, M., M.B. Cremonte. 1997. Correlación cronológica del yacimiento de Volcán con sitios de los Valles Orientales (Sector Meridional, Quebrada de Humahuaca). Avances en Arqueología 3: 191-212.

Gheggi, M.S. 2012. Patologías orales, dieta y modo de vida 
en Esquina de Huajra (Quebrada de Humahuaca, Jujuy). Revista Argentina de Antropología Biológica 14 (1): 65-77.

Gonzalez, P.N., V. Bernal y S.I. Pérez. 2011. Analysis of sexual dimorphism of craniofacial traits using geometric morphometric techniques. International Journal of Osteoarchaeology 21: 82-91.

Gunz, P., P. Mitteroecker y F. L. Bookstein. 2005. Semilandmarks in Three Dimensions. Slice, D.E., editor, Modern Morphometrics in Physical Anthropology, 73-98, Kluwer Academic/Plenum Publishers, New York.

Harvati, K., D. Weaver. 2006. Human cranial anatomy and the differential preservation of population history and climate signatures. Anatomical Record 288A: 1225-1233.

Howells, W.W. 1973. Cranial variation in man: a study by multivariate analysis of patterns of difference among recent human populations. Papers of the Peabody Museum of Archaeology and Ethnology. Cambridge, Cambridge Peabody Museum.

Hylander, W.L. 1977. In vivo bone strain in the Mandible of Galago crassicaudatus. American Journal of Physical Anthropology 46 (2): 309-326.

Imbelloni, J. 1924/25. Deformaciones intencionales del cráneo en Sudamérica. Polígonos craneanos aberrantes. Revista del Museo de La Plata 28: 329-407.

Klingenberg, C.P. 2011. MorphoJ: an integrated software package for geometric morphometrics. Molecular Ecological Resources 11: 353-357.

Krapovickas, P. 1969. La instalación aborigen en "Pucará de Yacoraite" (Prov. Jujuy, Rep. Argentina. Etnía 10: 8-12.

Lieberman, D. E., O. M. Pearson, y K. M. Mowbray. 2000. Basicranial influence on overall cranial shape. Journal of Human Evolution 38: 291-315.

Lieberman, D.E., G.E. Krovitz, F.W. Yates, M. Devlin y M. St. Claire. 2004. Effects of food processing on masticatory strain and craniofacial growth in a retrognathic face. Journal of Human Evolution 46: 655-677.

Mendisco, F., C. Keyser, C. Hollard, V. Seldes, A.E. Nielsen, E. Crubezy, y B. Ludes. 2011. Application of the iPLEX ${ }^{\mathrm{TM}}$ Gold SNP genotyping method for the analysis of Amerindian ancient DNA samples: Benefits for ancient population studies. Electrophoresis 32: 386-393.

Merlo, N., O. Mendonca, M.A. Bordach y M. Ruiz. 2005. Vida y Muerte en el Pucará de Yakoraite. Estudio de Osteología Humana. Cuadernos 29: 113-142.

Mitteroecker, P., Gunz, P. 2009. Advances in Geometric
Morphometrics. Evolutionary Biology 36: 235-247.

Nielsen, A.E. 1989. "La ocupación indígena del territorio Humahuaca oriental durante los períodos de Desarrollos Regionales e Inka". Tesis Doctoral. Universidad Nacional de Córdoba, Córdoba.

Nielsen, A.E. 1996. Demografía y cambio social en la Quebrada de Humahuaca (Jujuy, Argentina), 700-1535 DC. Relaciones de la Sociedad Argentina de Antropologia XXI: 307-385.

Nielsen, A.1997. Tiempo y Cultura Material en la Quebrada de Humahuaca 700-1650 dC. Instituto de Interdisciplinario de Tilcara, Universidad de Buenos Aires, Tilcara, Jujuy.

Nielsen, A.E. 2001. Evolución social en la Quebrada de Humahuaca AD 700-1536. Berberian, E., A. Nielsen, editores, Historia Argentina Prehispánica, Tomo I, 171264, Editorial Brujas, Córdoba.

Nielsen, A.E. 2003. La edad de los Auca Runa en la Quebrada de Humahuaca (Jujuy, Argentina). Memoria Americana 11: 74-107.

Nielsen, A.E. 2007. Bajo el hechizo de los emblemas: políticas corporativas y tráfico interregional en los Andes Circumpuneños. Nielsen, A.E., M.C. Rivolta, V.Seldes, M.M. Vázquez, P.H. Mercolli, compiladores, Producción y circulación prehispanicas de bienes en el sur andino, 393411, Editorial Brujas, Córdoba.

Nielsen, A.E., M.C. Rivolta. 1997. Asentamientos Residenciales de Ocupación Breve en la Quebrada de Humahuaca (Jujuy, Argentina). Chungará 29 (1): 19-33.

Palma, J. 1997/98. Ceremonialismo mortuorio y registro arqueológico: apuntes sobre complejidad social. Relaciones de la Sociedad Argentina de Antropología 22-23:179-201.

Palma, J. 1998. Curacas y señores. Instituto Interdisciplinario Tilcara, Facultad de Filosofía y Letras, UBA, Buenos Aires.

Peres-Neto, P.R., D.A. Jackson. 2001. How well do multivariate data sets match? The advantages of a Procrustean superimposition approach over the Mantel test. Oecologia 129:169-178.

Pérez, S.I. 2006. Influencia de la deformación artificial del cráneo sobre la morfología facial: Implicancias para los estudios de relaciones evolutivas inter-poblacionales. Revista Argentina de Antropología Biológica 8 (1): 37-55.

Pérez, S.I. 2007. Artificial cranial deformation in South America: A geometric morphometrics approximation. Journal of Archaeological Science 34: 1649-1658.

Pérez, S. I. y L. R. Monteiro. 2009. Nonrandom factors 
in modern human morphological diversification: a study of craniofacial variation of southern south American populations. Evolution 63 (4): 978-993.

Pérez, S. I., V. Bernal, P. N. González, M. Sardi y G. G. Politis. 2009. Discrepancy between cranial and DNA data of Early Americans: Implications for American Peopling. PLoSone 4 (5): e5746.

Pérez, S.I., V. Lema, J.A.F.Diniz-Filho, V. Bernal, P.N. Gonzalez, D. Gobbo y H.M. Pucciarelli. 2011. The role of diet and temperature in shaping cranial diversification of South American human populations: an approach based on spatial regression and divergence rate tests. Journal of Biogeography 38 (1): 148-163.

Peterson, J., P.C. Dechow. 2003. Material properties of the human cranial vault and zygoma. The Anatomical Record 274A (1): 785-797.

Raffino, R., R. Alvis 1993. Las ciudades Inka en Argentina: arqueología de La Huerta de Humahuaca. El sistema de doblamiento prehispánico. Raffino, R., editor, Inka, arqueología, historia y urbanismo del Altiplano Andino, 37-76, Editorial Corregidor, La Plata.

Relethford, J.H. 1994. Craniometric variation among modern human populations. American Journal of Physical Anthropology 95: 53-62.

Rivolta, M.C., C. Otero y V. Seldes. 2010. Actualización de la problemática del sitio Angosto Chico (Jujuy, Argentina). Arqueología 16: 87103.

Roseman, C.C. 2004. Detecting interregionally diversifying natural selection on modern human cranial form by using matched molecular and morphometric data. Proceedings of the Natural Academy of Sciences USA 101: 12824-12829.

R-Development Core Team. 2012. R: a language and environment for statistical computing. R Foundation for Statistical Computing, Vienna, Austria. http://www. R-project.crg

Sánchez, S., G. Sica. 1991. Algunas reflexiones acerca de los Tilcaras. Avances en Arqueología 1: 81-99.

Sardi, M.L., H.M. Pucciarelli. 2001. Influencia de la deformación artificial indefinida en las comparaciones craneanas interpoblacionales. Revista Argentina de Antropología Biológica 3 (1): 23-34.

Sardi, M., F. Ramírez-Rozzi, R. González-José, y H. M. Pucciarelli. 2005. South Amerindian craniofacial morphology: diversity and implications for Amerindian evolution. American Journal of Physical Anthropology 128: 747-756.
Seldes, V. 2006. Bioarqueología de poblaciones prehistóricas de la Quebrada de Humahuaca (Jujuy, Argentina). Estudios Atacameños 31: 47-61.

Seldes, V. 2008/2010 Las sociedades corporativas desde el registro bioarqueológico: Los Amarillos (Quebrada de Humahuaca, Jujuy). Cuadernos del Instituto Nacional de Antropología y Pensamiento Latinoamericano 22: 203215.

Seldes, V. 2012 Hacia una bioarqueología Social. La Quebrada de Humahuaca en perspectiva histórica. Editorial Académica Española.

Shimada, I., C. Schaaf, L. G. Thompson y E. Mosley Thompson. 1991. Cultural impacts of severe droughts in the prehistoric andes: application of a 1500 - year ice core precipitation record. World Archaeology 22: 247 - 270.

Skelton, R.R., H.M. McHenry. 1992. Evolutionary relationships among early hominids. Journal of Human Evolution 23 (4): 309-349.

Tarragó, M., M.E. Albeck 1997. Fechados radiocarbónicos para el sector medio de la Quebrada. Avances en Arqueología 3: 101129.

Thompson, L. G., E. Mosley-Thompson, F. Bolzan y B. R. Koci. 1985. A 1500- year record of tropical precipitation in ice cores from the Qulecaya Ice Cap, Perú. Science 229: $971-973$.

Thompson, L.G., E. Mosley-Thompson, K.A. Henderson. 2000. Ice-core palaeoclimate records in tropical South America since the Last Glacial Maximum. Journal of Quaternary Science 15 (4): 377-394.

Varela, H., J. Cocilovo, I. Baffi, y S. Valdano. 1999. La población antigua de la Quebrada de Humahuaca y sus relaciones biológicas con áreas aledañas. Revista Española de Antropología Biológica 20: 7-24.

Varela, H., C. Paschetta y J. Cocilovo. 2004 Análisis de las relaciones biológicas entre poblaciones del N.O.Argentino por medio de caracteres métricos. Relaciones de la Sociedad Argentina de Antropología XXIX: 317-330.

Varela, H.V., T.G. O’Brien y J. Cocilovo. 2008. The Genetic Divergence of Prehistoric Populations of the South-Central Andes as Established by Means of Craniometric Traits. American Journal of Physical Anthropology 137: 274-282.

Varela, H.V., J. Cocilovo y T.G. O’Brien. 2012. Evolución de las Poblaciones Prehistóricas del Área Andina Centro-Sur: Deriva Genética, Migración y Selección Natural. Antropo 28: 9-22. 